\title{
Dificuldades de aprendizagem e nas relações interpessoais do deficiente auditivo numa sala de aula de uma escola regular
}

\author{
Andréa Moraes Campos* \\ Carla Lima de Souza* \\ Daniela dos Santos Almeida* \\ Roberto Paulo Correia de Araújo**
}

\begin{abstract}
Resumo
O presente estudo trata da integração do indivíduo deficiente auditivo na escola regular, tendo como referência local a escola Manoel Vitorino, da rede pública, onde está matriculado um grande número de alunos com deficiência auditiva. É um fato real, porém novo, a inclusão do deficiente auditivo no ambiente social de escola comum, implicando em relevantes questionamentos quanto às formas como se dá tal inclusão. Buscou-se identificar os problemas encontrados nas relaçôes interpessoais entre os deficientes auditivos e entre estes e os alunos que ouvem normalmente, assim como determinar as dificuldades de aprendizagem encontradas por esses indivíduos, tendo a sala de aula como o contexto social específico. A metodologia utilizada consistiu em aplicação de questionário-formulário ao corpo discente e entrevista ao corpo docente da escola. Os dados coletados apontam o estabelecimento de relaçóes interpessoais entre o deficiente auditivo e indivíduos ouvintes como um aspecto positivo do processo de inclusão, embora, no que tange ao processo de aprendizagem, haja um prejuízo causado pela ineficiência da didática aplicada, pois não há qualquer forma de planejamento específico e amplo que capacite professores e funcionários da instituição a atenderem às necessidades do deficiente auditivo. Soma-se a isso a falta de acompanhamento profissional extraclasse, imprescindível neste caso.
\end{abstract}

Palavras-chave: Deficiente auditivo. Escola regular. Inclusão. Aprendizagem.

\section{INTRODUÇÃO}

A deficiência auditiva afeta um em cada 1.000 indivíduos da população mundial (LOPES FILHO, 1997). Entre os brasileiros, é a segunda maior deficiência comprovada (LANDIM, 2000). Com base em critérios audiológicos, diversos autores consideram estado de "surdez" as perdas acima de $90 \mathrm{~dB}$, enquanto para outros só há perda total da audição a partir de $120 \mathrm{~dB}$.
Entre os deficientes auditivos, alguns já nascem com perda auditiva e outros perdem a audição após o nascimento, seja na fase pré-lingüística, seja depois de adquirir a língua materna, resultando, portanto, em prognósticos distintos (COUTO-LENZI, 1997). Clinicamente, exames audiológicos são realizados para se determinar o tipo e o grau da perda. De acordo com as características detectadas, podem ser indicados aparelhos de amplificação sonora, vi-

\footnotetext{
*Acadêmica do Curso de Fonoaudiologia. Instituto de Ciências da Saúde. UFBA.

** Professor Adjunto. Instituto de Ciências da Saúde. UFBA (Orientador).

Av. Reitor Miguel Calmon, s/n, Vale do Canela

40.110-100 - Salvador Bahia Brasil

Tel.: (0xx71)245-8602 / 8339

Fax: (0xx71)245-8917

E-mail:ics@ufba.br
} 
sando a contribuir para o aumento significativo da audição dos indivíduos afetados.

Segundo Balieiro (1989), a ciência, ao contribuir com a construção do conhecimento sobre a audição do ser humano, também desenvolve meios para prevenir suas alteraçôes (prevenção primária), para detectá-las o mais cedo possível, ou mesmo para minimizá-las (prevenção secundária). Estabelecidas as dificuldades encontradas pelo deficiente auditivo em função da ruptura do seu feedback auditivo, náo se deve desconsiderar o potencial cognitivo, por ser ele dotado de outras formas perceptivas que contribuem para a formação do seu processo gnóstico.

O portador de surdez tem as mesmas possibilidades de desenvolvimento da pessoa ouvinte, precisando, tão somente, ter supridas suas necessidades especiais (RINALDI, 1998). Utilizando-se a audição residual que ainda exista, com amplificaçâo eficaz e boa habilidade de leitura labial, as crianças com perda severa $(60 \mathrm{a}$ $90 \mathrm{~dB}$ ) poderão ser capazes de se comunicar satisfatoriamente com o mundo normal dos que dispōem de audição. Em casos de perdas superiores a $90 \mathrm{~dB}$, recomenda-se a utilização precoce de "poderosos" dispositivos de amplificação associados aos programas pedagógicos específicos. Perelló e Tortosa (1968 apud COUTOLENZI, 1997) afirmam que até mesmo os surdos profundos, que não têm preservadas as frequiências de fala, podem beneficiar-se de implantes, dispositivos atualmente já disponíveis no Brasil.

Importantes achados científicos demonstram que o deficiente auditivo pode organizar seu mundo a partir da integridade dos demais sentidos, uma vez que ele é um indivíduo com potencialidades cognitivas normais, em que pese a diferença auditiva implicar, muitas vezes, em sérios obstáculos ao convívio social (CICCONE, 1996).

O progresso científico, em particular no campo da audiologia, conjugado com as transformaçôes ideológicas da sociedade, possibilitaram a construçấo de novos paradigmas voltados para a educação do deficiente auditivo. Para Harrinson, Lodi e Moura (1997), a educação de crianças surdas é uma meta a ser alcançada. Atingir uma educação verdadeira, fazendo com que essas crianças desenvolvam toda a sua potencialidade e se integrem plenamente na sociedade, participando dos fatos que as cercam, relacionando-se com indivíduos surdos e ouvintes, ultrapassa os limites de um país, pois mobiliza educadores e pesquisadores em todo o mundo, com a finalidade de reavaliar e propor novas perspectivas educacionais.

Estabelecida a relação entre o grau de perda, o período de aquisição e o comprometimento social e cognitivo do deficiente, selecionamse as estratégias de habilitação ou reabilitação que devem ser aplicadas a cada caso, com o objetivo de auxiliá-lo a desenvolver o máximo de habilidades na intercomunicação.

O desenvolvimento intelectual de uma criança está diretamente relacionado à linguagem. Assim, qualquer rota estabelecida no labirinto neurológico do deficiente auditivo que possibilite o entendimento da linguagem deve ser seguida. A meta primária é descobrir as habilidades inatas da linguagem; secundariamente, o alvo é a expressão oral inteligível, uma habilidade que depende da aquisição de um alto grau de competência na língua (NORTHERN; DOWNS, 1989). Não apenas o treinamento auditivo e a leitura labial facilitariam a sua comunicação; é também importante o aprendizado de indícios lingüísticos, visuais e situacionais (BOONE; PLANTE, 1994).

Uma vez que o desenvolvimento da linguagem e o processo de internalização dos conceitos caminham conjuntamente com a comunicação, é vital o papel desempenhado pela audição tanto no desenvolvimento da linguagem como na construção e clarificação de conceitos. No caso do deficiente auditivo, esse processo torna-se não só mais lento como mais árduo (LOUIS FANT,1963 apud NORTHERN; DOWNS, 1989).

O educador de surdos se depara com as limitações por estes enfrentadas, já que as barreiras se apresentam logo no primeiro elemento do processo de comunicação. Sua mente é privada das ricas informaçôes sensoriais que são captadas através da audição. Em consequiência, 
freqüentemente eles têm um pobre suprimento de símbolos para classificar, categorizar e armazenar. Novos símbolos são dificilmente obtidos. As crianças surdas trabalham com operaçôes mentais no nível concreto, uma vez que as operações abstratas, que requerem uma precisa codificação e decodificação, tornam-se mais difíceis para elas, por serem executadas com palavras, uma "mercadoria" de que nunca dispõem suficientemente. Esses deficientes raramente alcançam um grau de habilidade de linguagem suficiente para dominar as operações abstratas, mesmo depois de árduos esforços.

Enquanto a educação oferecida em instituiçóes segregadas passa a ser questionada, a inclusão se reflete no desenvolvimento de estratégias que procuram proporcionar uma equalização genuína de oportunidades (SANTOS, 1997). A atual política educacional, caracterizada por favorecer a integração de alunos portadores de necessidades especiais e baseada na declaração de Salamanca — aprovada, em jun.1994, por mais de 392 representaçôes governamentais e mais de 25 organizaçôes internacionais, entre as quais a Unesco e as Naçôes Unidas -, tem como objetivo promover a educação para todos (PERLIN; QUADROS, 1997). A legislação brasileira, representada pela Constituição promulgada em 1988 e pela LDB (Lei no 9394/ 96), prevê a integração do aluno com necessidades especiais no sistema regular de ensino (RINALDI, 1998).

Mas integração não significa a mera inserção do portador de necessidades educativas especiais numa classe regular. Se a inserção limita-se à introdução física desse educando, a integração implica em aceitação, devendo a comunidade escolar ser conscientizada da importância da convivência de alunos especiais em seu meio (SÁ, 1997). A verdadeira integração implica em reciprocidade (RINALDI, 1998). À atenção especial da família deve somar-se a de profissionais especializados, aptos a um criterioso processo de avaliação, a fim de serem fornecidas as condições de adaptação e de aprendizagem.

A grande diversidade existente entre sujeitos portadores de deficiência auditiva não permite determinar uma única proposta educacio- nal. Cada um possui um grau de capacidade de utilização da audição residual e diferentes níveis de desenvolvimento da linguagem oral. Se parcela significativa dos deficientes auditivos necessita de condiçõos especiais, fica reservada às escolas especiais a incumbência de educá-los. Entretanto, a escola regular corresponde também a uma das possibilidades de educação desses deficientes, que deve ter por objetivo o bemestar e a formação total, viabilizando o desenvolvimento de suas potencialidades. Portanto, as longas discussões a respeito de qual a melhor alternativa educacional para o deficiente auditivo não são pertinentes (BALIEIRO, 1989).

O presente estudo buscou avaliar o processo de inclusão dos deficientes auditivos numa escola pública regular de Salvador, Bahia, considerada como referência para a educação de alunos portadores de deficiências, sobretudo auditiva, identificar as dificuldades existentes nas relações interpessoais e na aprendizagem destes alunos e, em conseqüência, analisar a efetividade do processo de inclusão, com vistas a apontar possíveis aspectos a serem redirecionados.

\section{MATERIAIS E MÉTODOS}

\section{Constituição da amostra}

A amostra estratificada para a realização do presente estudo constituiu-se de 115 alunos regularmente matriculados, em 2000, na escola de ensino fundamental Manoel Vitorino, situada no bairro de Brotas, Salvador, Bahia, de ambos os sexos, com média de idade equivalente a 21,5 anos, sorteados aleatoriamente, distribuídos em dois grupos: 92 ouvintes normais e 23 deficientes auditivos. Contando com 17 salas de aula, esta escola funciona nos três turnos e atende 1.748 estudantes. Os alunos com deficiência auditiva integram as turmas regulares a partir da $5^{\mathrm{a}}$ série e se distribuem pelos três turnos, freqüentando cinco turmas no turno matutino, uma no vespertino e oito no noturno. Por ocasião da constituição da amostra, havia um único deficiente auditivo matriculado no turno vespertino, daí terem sido selecionados estudantes dos turnos matutino e noturno. 


\section{Coleta de dados}

A fim de viabilizar a coleta de dados de acordo com a legislação vigente, foi elaborado o termo de consentimento a ser assinado pela Direção da Escola, assim como o termo de autorização a ser firmado pelos professores, objetivando a gravação, em fita cassete, das entrevistas. Para o registro dos dados, foram utilizados os seguintes instrumentos: questionárioformulário destinado aos alunos deficientes auditivos; questionário-formulário destinado aos alunos ouvintes normais e roteiro da entrevista a ser realizada com os professores.

\section{RESULTADOS E DISCUSSÃO}

\section{Relações sociais do deficiente auditivo na escola regular}

A integração do aluno deficiente auditivo numa classe regular tem como finalidade promover sua participação num contexto social mais amplo, constituído de indivíduos ouvintes, garantindo-lhe, dessa forma, os direitos de igualdade social e permitindo-lhe maior contato com a língua oral, tendo em vista que a aprendizagem de uma língua só se efetiva quando se tem contato direto com os falantes desta língua (RINALDI, 1998). Para que a integração seja efetiva, é preciso que o deficiente auditivo sinta-se parte do grupo, o que tem sido facilitado, segundo Balieiro (1989), pela tendência atual, por parte da sociedade, em respeitar e aceitar indivíduos portadores de deficiências. O estabelecimento de relações interpessoais entre o deficiente auditivo e o ouvinte normal depende da motivação de ambas as partes em contornar os obstáculos comunicativos, da aceitação, por parte dos alunos ouvintes, da diferença do outro, bem como do posicionamento equilibrado, no que se refere à auto-estima, por parte do deficiente auditivo.

Para o presente trabalho, foram reunidos dados significativos que expressam a inter-relação deficientes auditivos/ouvintes normais no contexto da realidade em que estão inseridos, na perspectiva de projeção desta problemática para outras realidades.

As respostas colhidas a alunos ouvintes normais demonstram como eles encaram a presença de alunos com deficiência auditiva em sua classe e revelam uma certa heterogeneidade de posicionamento entre os alunos dos turnos matutino (FIGURA 1) e noturno (FIGURA 2).

Os alunos que consideram positiva a presença de colegas com deficiência auditiva totalizam $51,3 \%$ no turno matutino e $30,18 \%$ no turno noturno, percentuais que indicam uma busca de interação dos ouvintes interessados em estabelecer uma relação de comunicação com os deficientes auditivos, independentemente da linguagem utilizada. O aprendizado da Língua Brasileira de Sinais (LIBRAS) declarado pelos ouvintes é um estímulo significativo nessa interrelação. Os alunos que encaram com normalidade essa presença $(30,76 \%$ no turno da manhã e 30,18\% no turno da noite) reconhecem e enfatizam os direitos humanos dos portadores de deficiência auditiva. A integração do deficiente auditivo é benéfica não só para ele, pois os outros alunos são incentivados a desenvolver uma atitude despojada de preconceitos, uma vez que vivenciam as "diferenças".

Por outro lado, os percentuais de $15,38 \%$ (turno matutino) e de $18,8 \%$ (turno noturno) expressam um certo grau de rejeição aos colegas deficientes auditivos, devido, muito provavelmente, à dificuldade na comunicação entre ouvintes e deficientes auditivos e/ou às dificuldades de aprendizagem apresentadas pelos últimos.

Em virtude da falta de coerência entre as respostas obtidas e o que foi perguntado, desprezaram-se alguns dados. O percentual de $20,7 \%$ referente aos alunos do turno noturno se deveu, provavelmente, ao desinteresse manifestado ao responder a questão formulada.

Uma vez que o bom relacionamento entre indivíduos é produto da interação comunicativa, e tendo em vista os reais obstáculos na relação ouvinte normal/deficiente auditivo, os alunos ouvintes foram também questionados quanto à existência de deficientes auditivos no seu gru- 


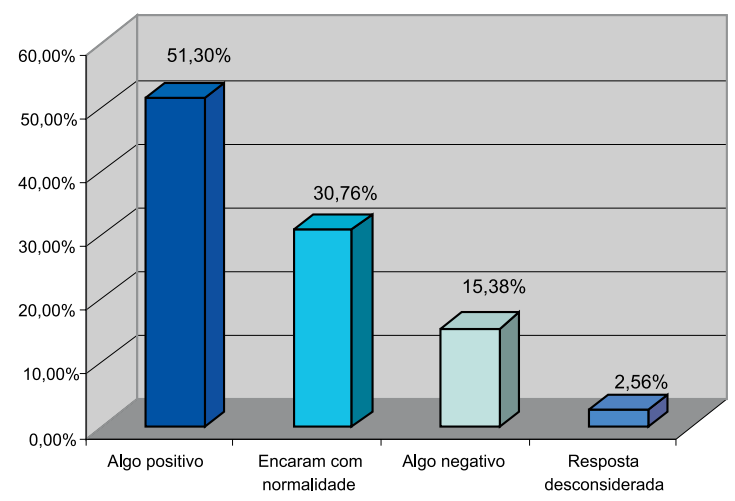

Figura 1 - Opinião dos ouvintes normais sobre a presença de colegas com deficiência auditiva (turno matutino)

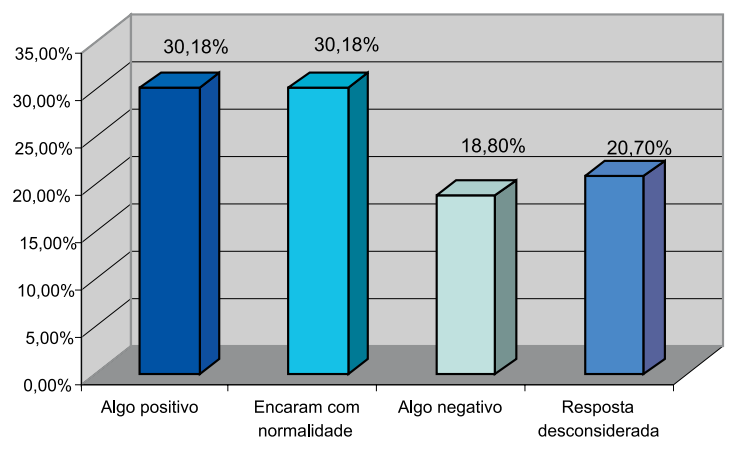

Figura 2 - Opinião dos ouvintes normais sobre a presença de colegas com deficiência auditiva (turno noturno)

po de amigos da escola. De uma parcela significativa $(88 \%)$ obteve-se resposta positiva.

Quanto aos deficientes auditivos, ao serem inquiridos sobre a existência de comunicação com todos os seus colegas, 91\% deles deram uma resposta afirmativa. Pormenorizando, porém, o seu relacionamento com os colegas, $60,9 \%$ indicaram que tinham maior contato com os próprios colegas deficientes auditivos; $30,4 \%$ mencionaram nomes tanto de alunos deficientes auditivos quanto de ouvintes normais; os $8,7 \%$ restantes citaram apenas nomes dos alunos que ouvem normalmente (FIGURA 3).

Estes dados confirmam que o tipo de amizade entre deficiente auditivo e ouvinte, na

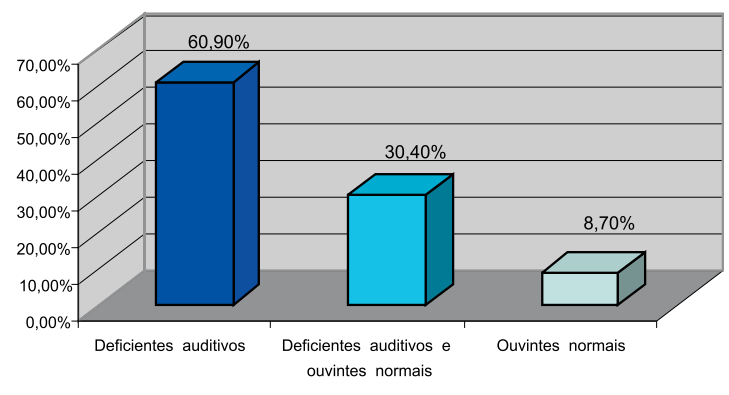

Figura 3 - Relacionamento do deficiente auditivo com os seus colegas

maioria das vezes, não é próxima. $\mathrm{Na}$ medida em que esses deficientes procuram achegar-se às pessoas com as mesmas características, estaria implícita a sua busca da identidade. Acrescentem-se a isso os depoimentos do corpo docente, que definem a comunicação entre deficiente auditivo e ouvinte como restrita e revelam que os deficientes auditivos se comunicam mais entre si, o que se deve, em última análise, às barreiras lingüísticas que dificultam uma melhor intercomunicação.

O princípio da inclusão prevê a integração do deficiente auditivo com os que ouvem normalmente, dando-lhes a oportunidade "de enfrentar o desafio de participar da sociedade ouvinte" e "estabelecer relaçôes que não são necessariamente mediadas pela surdez" (BALIEIRO, 1989, p.203). Isto exige um esforço adaptativo do deficiente para utilizar a audição residual, se existente, e desenvolver a capacidade de leitura labial e a expressão oral. Para o desenvolvimento dessas habilidades comunicativas é imprescindível um acompanhamento terapêutico fonoaudiológico (HARRISON; LODI; MOURA, 1997), o que não ocorre com os deficientes auditivos que fizeram parte do presente estudo e, certamente, com a maioria dos portadores de deficiência auditiva no Brasil.

O índice de dificuldade na comunicação com os ouvintes normais declarado pelos deficientes auditivos pesquisados foi substancial (61\%). A divergência dos símbolos lingüísticos utilizados na comunicação explicaria essas limitações comunicativas. Por outro lado, $22 \%$ de- 
clararam também alguma dificuldade na intercomunicação com outros deficientes auditivos.

A comunicação entre deficiente auditivo e ouvinte normal exige adaptaçôes de ambas as partes. No que se refere à recepção da mensagem, o deficiente auditivo se esforça em aprimorar a leitura labial e/ou utilizar sua audição residual, enquanto o ouvinte normal busca compreender a LIBRAS. Quanto à emissão, o deficiente auditivo tenta fazer-se compreender por gestos e/ou por alguma linguagem oral que tenha desenvolvido, enquanto o ouvinte normal lança mão de gestos, da LIBRAS e da fala, pausada ou em volume alto. A escrita pode ser considerada a linguagem comum entre eles, embora não seja a forma mais prática de comunicação por demandar tempo.

A Tabela 1 demonstra as formas de comunicação declaradas pelos ouvintes normais para se comunicar com o deficiente auditivo. Os gestos são a forma mais utilizada pelos alunos do turno matutino que ouvem normalmente para se comunicar com seus colegas portadores de deficiência auditiva $(46,2 \%)$. Uma parcela significativa declarou empregar diversos meios conjuntamente $(28,25 \%)$. Entre os alunos do turno noturno, não houve destaque para o uso de uma modalidade específica de comunicação. Os gestos foram o meio mais apontado (26,42\%), seguido de perto por diferentes formas de comunicação $(22,65 \%)$.

No turno noturno, em que há em média 1,8 deficientes auditivos por sala, os alunos ouvintes que utilizam gestos procuram criá-los, visto que não dominam a LIBRAS. Os do turno matutino, mais expostos à linguagem de sinais, pois há, em média, 3,6 deficientes auditivos por turma, lançam mão dessa linguagem. O contato maior com alunos portadores de deficiência auditiva provocou uma adaptação por parte dos alunos que ouvem normalmente, o que demonstra um ponto positivo: o grau de receptividade desses alunos aos indivíduos portadores de deficiência. Mas, por outro lado, sugere que um dos objetivos do processo de inclusão não está sendo concretizado - o de induzir o desenvol-
Tabela 1- Formas utilizadas pelos ouvintes normais na comunicação com os deficientes auditivos

\begin{tabular}{l|rr|rr}
\hline \multirow{2}{*}{ Forma utilizada } & \multicolumn{2}{|c|}{$\begin{array}{c}\text { Turno } \\
\text { matutino }\end{array}$} & \multicolumn{2}{c}{$\begin{array}{c}\text { Turno } \\
\text { noturno }\end{array}$} \\
\cline { 2 - 5 } & $\mathrm{N}^{\circ}$ & \multicolumn{1}{c}{$\%$} & $\mathrm{~N}^{\circ}$ & $\%$ \\
\hline Gestos & 18 & 46,2 & 14 & 26,42 \\
Escrita & 2 & 5,2 & 11 & 20,75 \\
Fala & 6 & 15,4 & 10 & 18,87 \\
Outros & 1 & 2,5 & 1 & 1,88 \\
Mais de uma resposta & 11 & 28,25 & 12 & 22,65 \\
Não se comunica & 1 & 2,5 & 4 & 7,55 \\
Sem resposta & 0 & 0 & 1 & 1,88 \\
Total & 39 & 100 & 53 & 100 \\
\hline
\end{tabular}

Fonte: Pesquisa de campo / 2000

vimento da língua oral, na medida do possível, a partir da convivência num meio em que esta seja majoritária —-, provavelmente pela falta de acesso desses deficientes a profissionais especificamente qualificados para fornecer subsídios ao desenvolvimento da linguagem verbal.

A opinião dos alunos ouvintes quanto à forma de tratamento que dispensam aos colegas portadores de deficiência auditiva está expressa na Tabela 2 .

Muito embora os alunos ouvintes tenham respondido majoritariamente que dispensam um tratamento normal aos colegas deficientes (74,3\% no turno diurno e $54,8 \%$ no noturno), existe, segundo informações dos professores, alguma resistência em aceitar a participação de colegas deficientes auditivos em seu grupo de trabalho em classe, devido às limitaçôes comunicativas e de aprendizagem. Em contrapartida, os deficientes auditivos procuram formar grupos de trabalho entre si.

Procurou-se também apurar o tratamento dispensado pelos professores aos seus alunos portadores de deficiência auditiva. No julgamento dos alunos ouvintes (TABELA 3), os professores do turno matutino demonstram tratar os deficientes auditivos com mais atenção $(56,4 \%)$, procurando atender às suas demandas indivi- 
Tabela 2 - Forma de tratamento dispensada pelos colegas ouvintes aos deficientes auditivos

\begin{tabular}{l|rr|rr}
\hline \multirow{2}{*}{ Forma utilizada } & \multicolumn{2}{|c|}{$\begin{array}{c}\text { Turno } \\
\text { matutino }\end{array}$} & \multicolumn{2}{c}{$\begin{array}{c}\text { Turno } \\
\text { noturno }\end{array}$} \\
\cline { 2 - 5 } & \multicolumn{1}{c}{$\mathrm{N}^{\circ}$} & \multicolumn{1}{c}{$\%$} & \multicolumn{1}{c}{$\mathrm{N}^{\circ}$} & \multicolumn{1}{c}{$\%$} \\
\hline Igual aos demais alunos & 29 & 74,3 & 29 & 54,8 \\
Com mais atenção & 8 & 20,5 & 13 & 24,55 \\
São discriminados & 0 & 0 & 8 & 15,0 \\
Outros & 0 & 0 & 0 & 0 \\
Sem resposta & 2 & 5,2 & 3 & 5,7 \\
Total & 39 & 100 & 53 & 100 \\
\hline
\end{tabular}

Fonte: Pesquisa de campo / 2000

dualmente. No turno noturno, esboçou-se uma tendência de tratá-los tal como os demais alunos $(50,9 \%)$, provavelmente por serem menos numerosos por turma, muito embora, paralelamente, o significativo percentual de 45,3\% deixe perceber, segundo os alunos ouvintes, um tratamento mais atencioso dispensado aos deficientes auditivos.

Esses dados se contrapõem aos colhidos no depoimento da maioria dos professores. Eles afirmam tratar os alunos portadores de deficiência auditiva da mesma maneira que os alunos ouvintes, muito embora reconheçam um maior cuidado em certificar-se se os deficientes estão tendo aproveitamento. $\mathrm{Na}$ realidade, ao procurar atender às necessidades específicas dos deficientes auditivos, os professores, de certa forma, são interpretados como se lhes dispensassem uma maior atenção. Tentar suprir as necessidades específicas dos deficientes auditivos não significa necessariamente tratá-los com mais atenção. Aliás, na prática, essas necessidades não são supridas, conforme se verá adiante.

A partir dos dados colhidos, é correto afirmar-se que há uma tendência de os alunos ouvintes considerarem importante a inclusão do deficiente auditivo. Para que essa inclusão se concretize na íntegra, mediante uma concepção humanizadora vislumbrada por todos, é imperioso pôr-se em prática uma política de conscientização que supere o conceito de defi-
Tabela 3 - Opinião dos alunos ouvintes quanto à forma de tratamento dispensada aos deficientes auditivos pelos professores

\begin{tabular}{l|rr|r|r}
\hline \multirow{2}{*}{ Forma utilizada } & \multicolumn{2}{|c|}{$\begin{array}{c}\text { Turno } \\
\text { matutino }\end{array}$} & \multicolumn{2}{c}{$\begin{array}{c}\text { Turno } \\
\text { noturno }\end{array}$} \\
\cline { 2 - 5 } & \multicolumn{1}{c}{$\mathrm{N}^{\circ}$} & \multicolumn{1}{c}{$\%$} & \multicolumn{1}{c}{$\mathrm{N}^{\circ}$} & \multicolumn{1}{c}{$\%$} \\
\hline Igual aos demais alunos & 13 & 33,3 & 27 & 50,9 \\
Com mais atenção & 22 & 56,4 & 24 & 45,3 \\
São discriminados & 0 & 0 & 0 & 0 \\
Outros & 3 & 7,7 & 0 & 0 \\
Sem resposta & 1 & 2,6 & 2 & 2,5 \\
Total & 39 & 100 & 53 & 100 \\
\hline
\end{tabular}

Fonte: Pesquisa de campo / 2000

ciência presente em metodologias pedagógicas preconceituosas e segmentadoras.

\section{Dificuldades de aprendizagem do deficiente auditivo em uma escola regular}

Os resultados do presente estudo colocam em evidência os reais objetivos inerentes à proposta de inserção do deficiente auditivo na escola regular. As informações obtidas demonstram as limitações enfrentadas por ele, limitaçôes que provavelmente poderiam ser superadas ao se considerar o processo de inclusão como humanizador, capaz de inserir o deficiente auditivo e suas diferenças em um contexto mais socializante. Todavia, incluir pressupôe, também, construir o processo de aprendizagem do deficiente.

As estatísticas demonstram a significativa quantidade de alunos deficientes auditivos que apresentam problemas de aprendizagem. Todos os deficientes auditivos abordados para o presente trabalho atribuíram ao déficit auditivo suas limitações na aprendizagem; 96\% deles declararam não acompanhar bem as aulas e $74 \%$ não assimilar o conteúdo veiculado. As dificuldades elencadas - consenso em quase toda amostra de deficientes auditivos - foram: não-entendimento do que o professor fala; não-entendimento, pelo professor, do que eles falam; desconhecimento da LIBRAS pelo professor; necessidade de qualificação do docente; ausência de mate- 
rial didático adequado às suas necessidades; dificuldade em prestar atenção; inibição para tirar dúvidas.

Esses mesmos pontos foram destacados pelos professores, tendo sido ressaltado que, em razão da assimetria na comunicação entre eles e os alunos deficientes auditivos, existe grande dificuldade na transmissão de conteúdos, principalmente no que tange à definição de conceitos, como, por exemplo, na área de Matemática, os de "radiciação" e "denominador", e no esclarecimento do significado de certas palavras desconhecidas.

Em função disso, deve-se salientar que um déficit auditivo tende a comprometer a integridade das informaçóes sensoriais supridas basicamente pela linguagem auditivo-oral, o principal modo de comunicação humana. Essa condição orgânica somada às condiçôes acústicas da sala de aula, à ausência de adaptaçôes eficazes no método pedagógico e à falta de acompanhamento terapêutico na habilitação do uso do resíduo auditivo fazem com que o deficiente auditivo tenha dificuldade em acompanhar as aulas, o que pode gerar falta de motivação.

Através das entrevistas, os professores informaram que, para contornar essas dificuldades, o aluno deficiente auditivo geralmente esclarece suas dúvidas com o colega ouvinte ao lado ou com colegas também deficientes auditivos, não tendo o hábito de esclarecê-las com o professor. Grande parte dos professores procura amenizar esses agravantes falando em frente ao deficiente auditivo, para facilitar a leitura labial, e/ou utilizando sempre o quadro-de-giz para expor o conteúdo das aulas.

A dificuldade de assimilar o conteúdo tem como causa principal a dificuldade em acompanhar as aulas. Acrescenta-se a isso o fato de o deficiente auditivo apresentar pobreza de vocabulário, cuja apreensão e expansão se dá principalmente através do contato com a língua oral, resultando em prejuízos na obtenção de infor- mações tanto de forma oral como escrita e na apreensão de idéias abstratas ou conceituais.

Deparando-se com barreiras no input do processo de comunicação, a criança portadora do distúrbio da audição tende a comprometer sua comunicação verbal e, conseqüentemente, sua articulação, voz e fluência. Considera-se uma possível ameaça à aprendizagem normal até mesmo uma perda auditiva baixa (15dB). Por conseguinte, com a importância da comunicação para tantos aspectos da aprendizagem, não é surpreendente que crianças com distúrbio de audição e, condicionalmente, de linguagem se encontrem sob risco de fracasso acadêmico. A Public Law 94-142 — The Education for All Handicapped Children Act —, aprovada pelo Congresso dos Estados Unidos em 1975, define o distúrbio de aprendizagem como "um distúrbio em um ou mais dos processos psicológicos básicos envolvidos na compreensão ou no uso da linguagem, falada ou escrita, que pode manifestar-se numa capacidade imperfeita de escutar, pensar, falar, ler, escrever, soletrar, ou efetuar cálculos matemáticos" (BOONE; PLANTE, 1994, p.116).

A audição é um canal de extrema importância para estabelecer o desenvolvimento cognitivo do indivíduo, ao assimilar experiências que, posteriormente, serão adaptadas. Para obter-se um bom desenvolvimento cognitivo e lingüístico, devem ser preservados mecanismos perceptivos simples e especiais, já que influenciam na construção da aprendizagem.

Procurando delinear o perfil do aluno deficiente auditivo quanto ao seu rendimento escolar, o presente trabalho remonta à discussão sobre o potencial cognitivo do indivíduo, mesmo quando submetido a um déficit em suas habilidades auditivas.

Em sua auto-avaliação, os alunos deficientes consideraram ótimo $(34,79 \%)$ ou bom $(47,82 \%)$ o seu rendimento escolar; apenas $13,04 \%$ apontaram um grau de aprendizagem regular (FIGURA 4). 


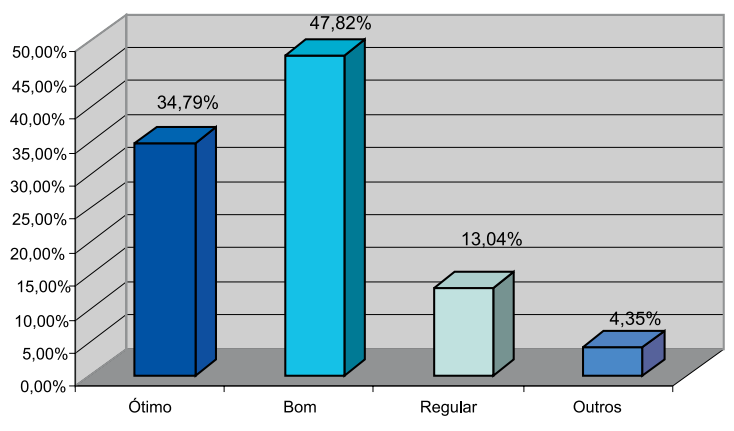

Figura 4 - Auto-avaliação dos alunos com deficiência auditiva quanto ao seu aproveitamento escolar

Quanto ao seu aproveitamento em matérias específicas (FIGURA 5), os deficientes analisados apontaram maiores dificuldades em matérias que demandam capacidade de percepção de idéias abstratas e amplo vocabulário da língua portuguesa, embora uma parcela enfrente dificuldades em todas as matérias. Matemática e Desenho/Educação Artística foram matérias consideradas mais fáceis, por trabalhar, respectivamente, com operações concretas e criatividade.

No processo de aprendizagem, estabelecese uma nova relação entre o potencial lingüístico e o auditivo. Pode-se observar que a linguagem e a comunicação desempenham papel importante em alguns aspectos do desenvolvimento cognitivo. De acordo com os estudos de Piaget, não se pode afirmar que haja causas lingüísticas ou pré-requisitos lingüísticos que determinem o desenvolvimento das estruturas mentais da criança. Para Deese (1976), "o emprego da linguagem na comunicação certamente ajuda a criança tanto a adquirir conhecimento como a aprender a ter outras perspectivas em relação ao seu próprio pensamento"; todavia "a linguagem pode fazer de nós pessoas informadas e comunicativas, mas não nos pode fazer seres pensantes".

Convém analisar-se o todo para se determinar a origem das dificuldades. O foco não deve centrar-se apenas no deficiente auditivo, mas na efetividade dos estímulos educacionais que lhe são fornecidos, buscando-se flagrar as inúmeras falhas existentes no processo de inclusão, que, desde sua denominação, já se manifesta de forma incoerente. $\mathrm{Na}$ verdade, a intenção não deveria ser a de incluir o aluno deficiente auditivo, mas a de integrá-lo a um contexto capaz de suprir da melhor forma as limitações que lhe são inerentes.

Cumpre ressaltar que a existência de escolas especiais para deficientes auditivos não descompromete as instituiçôes de ensino regular do seu papel educador, tendo em vista a responsabilidade social destas últimas para com qualquer indivíduo que busque seus serviços pedagógicos. A escola regular deve se tornar capaz de disponibilizar os recursos adequados ao atendimento das necessidades acadêmicas dos deficientes auditivos, facilitando o seu convívio nos diversos ambientes.

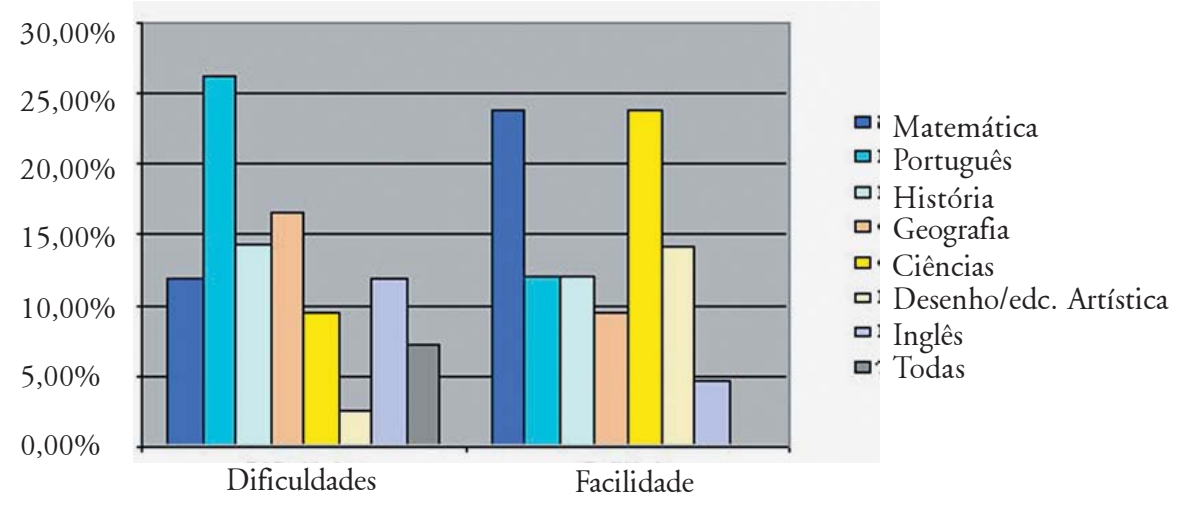

Figura 5- Auto-avaliação dos alunos com deficiência auditiva quanto ao seu aproveitamento em matérias específicas 
A hierarquia de responsabilidades não surge diretamente da instituição escolar, mas compromete os escalóes mais altos do Estado. Uma vez viabilizado o projeto de inclusão, cabe ao Estado torná-lo possível e funcional. Criar condições estruturais para o processo de integração do aluno é um dever do Estado. Fazer com que a estrutura funcione é um dever da escola. Para tanto, faz-se necessário não só o apoio pedagógico profissionalizado e capacitado para lidar com as diferenças do deficiente auditivo, como também o respaldo técnico de profissionais especializados que busquem suprir as carências psicológicas e fisiológicas do aluno deficiente auditivo. De forma mais clara: é de extrema importância a presença do fonoaudiólogo, do psicólogo e do psicopedagogo auxiliando o processo de aprendizagem do indivíduo deficiente, para que a política de inclusão se manifeste de forma a mais efetiva e funcional.

\section{CONCLUSÕES}

Face a essas constatações pode-se concluir que:

a) o estabelecimento de relações inter-pessoais com indivíduos não portadores de deficiência auditiva é um ponto positivo, talvez o maior, na inclusão do deficiente auditivo em uma classe regular;

b) as dificuldades de inter-relação encontradas pelo deficiente auditivo devem-se à assi- metria lingüística entre ele e os alunos ouvintes, fazendo com que busque a companhia de seus semelhantes;

c) as dificuldades em acompanhar as aulas e assimilar os conteúdos decorrem das próprias limitaçôes da deficiência auditiva, assim como da adaptação pedagógica ineficiente;

d) na escolha da alternativa educacional para o deficiente auditivo, devem-se levar em consideração as características e as necessidades individuais, ao invés de se valorizar um único método.

Tais conclusões permaneceriam vazias se não conduzissem a recomendações para que bons resultados sejam alcançados. Entre elas é possível apontar:

a) a construção, por parte do Governo, na qualidade de provedor da educação para todos os cidadãos, de uma estrutura capaz de atender às necessidades educacionais inerentes ao deficiente auditivo, estabelecidas e assumidas claramente as responsabilidades em todos os níveis;

b) a eliminação, por parte da escola, de qualquer forma de discriminação (positiva ou negativa) às limitaçôes dos alunos que necessitam de seus serviços pedagógicos;

c) a criação, nas escolas, de uma estrutura de apoio profissional específico, constituída por pedagogos, psicopedagogos, psicólogos e fonoaudiólogos, que auxiliem o deficiente auditivo no processo de integração no contexto escolar.

\title{
The difficulties found in the learning process and in the interpersonal relationship of people with hearing deficiency in a classroom of a regular school
}

\begin{abstract}
The present study is about individual's integration in a regular school, using the public school called Manoel Vitorino as a local reference, where is registered a great number of students with hearing deficiency. It is a real fact, even so a new one, the inclusion of hearing deficient in a common school, implying in important questions related to the way through which such inclusions occur. Facing these verifications, this study aimed to identify the problems found in the interpersonal relationships among people with hearing deficiency and among them and the students who have normal hearing, as well as determining the learning difficulties found by those individuals, using the classroom as a specific social context. The methodology
\end{abstract}


consisted of questionnaire-form applied to the students and interview used with the teachers of the school. The collected data points that the use of interpersonal relationships among hearing deficient and normal individuals as a positive aspect of the inclusion process, although as far as the learning process is concerned, there be a damage due to inefficiency of the applied didactics, because there is not any form of specific and wide plan that qualifies teachers and employees of the institution to assist the needs of the hearing deficient. It is added the lack of professional accompaniment outside the classroom which is indispensable in this case.

Keywords: Hearing deficient. Regular school. Inclusion. Learning.

\section{REFERÊNCIAS}

BALIEIRO, Clay Rienzo. O deficiente auditivo e a escola: relatos de algumas experiências. São Paulo: PUC, 1989.

BOONE, Daniel R.; PLANTE, Elena. Comunicação humana e seus distúrbios. 2.ed. Trad. de Sandra Costa. Porto Alegre: Artes Médicas, 1994.

CICCONE, Marta. Comunicação total. 2.ed. Rio de Janeiro: Cultura Médica, 1996.

COUTO-LENZI, Alpia. A integração das pessoas surdas. Informativo técnico-científico do INES, Rio de Janeiro, v.7, n.7, p.22-25, jun.1997.

DEESE, James. Psicolinguiística. Trad. de Ruth Wallace de Garcia Paula. Petrópolis: Vozes, 1976.

HARRINSON, Kathryn M. P.; LODI, Ana Cláudia B.; MOURA, Maria Cecília. Escolas e escolhas: o processo educacional dos surdos. In: LOPES FILHO, Otacílio de C. (Org.). Tratado de fonoaudiologia. São Paulo: Roca, 1997. cap. 17.

LANDIM, Raquel. Ouça a campanha de prevenção. Disponível em: <http://www.usp.br/jorusp/jusp410/ manchet/rep_res/rep_mt/pesqui 1.html> Acesso em: 04 jul. 2000.

LOPES FILHO, Otacílio de C. (Org.). Tratado de fonoaudiologia. São Paulo: Roca, 1997.

NORTHERN, Jerry L.; DOWNS, Marion P. Audição em crianças. 13.ed. Trad. de Maria Lúcia Maciel França Madeira et al. São Paulo: Manole, 1989.

PERLIN, Gladis T. P.; QUADROS, R. M. Educação de surdos em escola inclusiva? Informativo técnico-científico do INES, Rio de Janeiro, v.7, n.7, p.35-40, jun. 1997.

RINALDI, Giuseppe. Série deficiência auditiva. Brasília, DF: Ministério da Educação e do Desporto, Secretaria de Educação Especial, 1998. p.279-310. (N.6).

SÁ, Nídia R. L. Escola inclusiva: confrontando o paradigma. Informativo técnico-científico do INES, Rio de Janeiro, v.7, n.7, p.29-34, jun. 1997.

SANTOS, Mônica P. Educação especial, inclusão e globalização: algumas reflexões. Informativo técnicocientífico do INES, Rio de Janeiro, v.7, n.7, p.13-21, jun. 1997. 